\title{
Knowledge, practice and attitude of postnatal mothers towards postnatal exercises in a rural area of Tamil Nadu
}

\author{
Vishnu G Ashok ${ }^{1}$, Aazmi Mohamed ${ }^{2 *}$ \\ ${ }^{1,2}$ Assistant Professor, Dept. of Community Medicine, Sree Mookambika Institute of Medical Sciences, Kulasekharam, Tamil Nadu, India
}

\begin{abstract}
Introduction: Postpartum period or puerperium is the first six weeks after child birth, when the body undergoes major physiological changes. It is a critical transition time for women affecting significantly her physical as well as mental health.

Objectives: To assess the knowledge, practice and attitude of mothers towards postnatal exercise and to find out the association between demographic variables and knowledge, attitude, practice of postnatal exercise among mothers.

Materials and Methods: A cross sectional study, based on a semi structured pretested questionnaire which was distributed to mothers during a period of 1 month (December-January 2019) in a rural area of Kulasekharam, Kanyakumari district Tamil Nadu.

Results: In our study $22 \%$ of participants had adequate knowledge on postnatal exercise. $52 \%$ had a positive attitude towards postnatal exercise and $58 \%$ practiced postnatal exercises. A strong association has been found between knowledge, attitude, practice and some demographic variables (education, occupation and socioeconomic status).

Conclusion: Data revealed that our participants had poor Knowledge and Practice, but more than half had a positive attitude towards practicing postnatal exercise. Hence health education and awareness programs for pregnant women as well as their family members regarding postnatal exercise must be introduced right from the antenatal period to improve the current scenario.
\end{abstract}

Keywords: Postpartum, Post Natal, Exercise.

\section{Introduction}

Puerperium refers to the first six weeks following child birth and is a very stressful period for women worldwide due to the whirlwind of physical, biological and emotional changes that occur. It is when the pelvic organs return to the prepregnant state and reversal of the physiological changes of pregnancy occur. ${ }^{1}$ Most of the complications after birth can be prevented by adequate care, health education and adherence to proper diet and postnatal exercise regimen. Postnatal exercises are practiced soon after delivery which helps to improve the muscle tone of abdominal muscles, the pelvic floor muscles and also improve bladder, bowel function. These exercises speed up the recovery process after delivery. ${ }^{2}$ Researches prove that postnatal exercises can tackle many postnatal conditions like bladder and bowel incontinence, diastases recti and postpartum backache and also it makes the mother more relaxed thereby preventing depression and other pschyological disorders. ${ }^{3}$ Women should be encouraged to start with simple exercises soon after child birth and gradually progress to more strenuous ones. ${ }^{4}$ Kegel and breathing exercises are begun immediately after birth. Kegel exercise strengthen the pelvic floor muscles and vagina, while breathing exercises improve oxygen levels, decrease fatigue, decrease blood pressure, decrease depression and anxiety. Women who underwent caesarian section may start with aerobic exercises and delay abdominal exercises depending on their level of discomfort and other complicating factors. 5
Types of Postpartum Exercises: kegel exercise (Pelvic floor exercise), foot and leg exercise, relaxation exercise, abdominal exercise (abdominal breathing), pelvic tilting or rocking, head and shoulder raising, leg raising, knee rolling and hip hitching, ${ }^{6}$ abdominal tightening on outward breath, foot bending and foot stretching, ankle rotating, leg sliding, straight curl-up and diagonal curl-up. ${ }^{7}$ Many women are unaware of the types of postnatal exercises. Also some of the superstitions and customs in the society prohibit women from practicing postnatal exercises; hence women with newborn babies encounter many social barriers too in the rural areas of Tamil Nadu. But the most common barriers which impair the ability of women to participate in a regular exercise program are lack of assistance with childcare and insufficient time. ${ }^{8}$

\section{Objectives}

1. To assess the knowledge, practice and attitude of mother regarding postnatal exercises.

2. To find out the association between knowledge, attitude, practice of postnatal exercises and some demographic variables.

\section{Materials and Methods \\ Study design \\ Cross Sectional study.}

\footnotetext{
*Corresponding Author: Aazmi Mohamed, Dept. of Community Medicine, Sree Mookambika Institute of Medical Sciences, Kulasekharam, Tamil Nadu, India 


\section{Study setting}

The study was conducted in Sree Mookambika Institue of Medical Sciences, Kulasekharam, Kanyakumari district.

\section{Study population}

The postnatal mothers who attended the Gynaecology and Paediatric OPD during the study period.

\section{Sample size}

All the postnatal mothers who satisfied the inclusion criteria attended the Gynaecology and Paediatric OPD during the study period. So the sample size of the study was 50 .

\section{Inclusion criteria}

1. Who are willing to participate in the study

2. Who are available during the period of data collection

3. Who can understand and speak Tamil or English.

\section{Exclusion criteria}

1. Who are at 1 st postnatal day

2. Who are unaware of postnatal exercises

\section{Sampling technique}

Convenient Sampling

\section{Period of study}

1 month - December to January 2019

\section{Study tools}

1. Semi structured questionnaire

2. Modified Kuppusamy socioeconomic classification.

\section{Data collection}

A pretested semi structured questionnaire was used to collect data for the study. Knowledge, attitude and practice of each participant were scored. Knowledge was classified into adequate and inadequate. Attitude was classified as positive and negative.

\section{Statistical analysis}

Data was entered in MS. Excel sheet and was analyzed using SPSS version 16.0.

\section{Results}

The study population included 50 mothers in a rural area of Kulasekharam. The mean age of our study population was $27+/-3$ years. More than half of the population $(58 \%)$ were graduates and only $2 \%$ were illiterate. Most of them (44\%) were housewives. $52 \%$ of participants belonged to joint family and $48 \%$ of the participants belonged to nuclear family. More than half of the population (74\%) belonged to middle socioeconomic status and only $18 \%$ belonged to upper class. $54 \%$ of population had normal vaginal delivery. Majority of them (98\%) delivered in a hospital. The principal source of information on postnatal exercise as mentioned by the participants was from Doctors, Nurses and paramedical workers $(62 \%)$.

\section{Knowledge on postnatal exercise}

Most of the participants $(86 \%, 74 \%)$ were unaware of the right to time to start the postnatal exercises after caesarian section and vaginal delivery respectively. Only few participants $(26 \%, 14 \%)$ were aware of the correct time to start the exercises after vaginal and caesarian delivery respectively. Most of them (72\%) knew the benefits of postnatal exercises. But only $38 \%$ of the participants were aware of the disadvantage of not doing postnatal exercises. Only few (18\%) were aware about the type of exercises. Majority (82\%) didn't know about the types (Table 1). Overall only $22 \%$ of the participants had adequate knowledge about postnatal exercises (Table 1 Fig 1).

Table 1: Knowledge on postnatal exercises among postnatal mothers

\begin{tabular}{|l|c|c|}
\hline \multicolumn{1}{|c|}{ Characteristic } & Yes (\%) & No (\%) \\
\hline Adequate knowledge on postnatal exercise & 22 & 78 \\
Knowledge on correct time to start exercise & 26 & 74 \\
Vaginal delivery & 14 & 86 \\
Caesarian section & 72 & 28 \\
Knowledge on benefits of postnatal exercise & 38 & 62 \\
Awareness on disadvantages of not doing postnatal exercise & 18 & 82 \\
Awareness about the type of exercises & & \\
\hline
\end{tabular}

\section{Attitude on postnatal exercise}

$82 \%$ reported that postpartum exercises was necessary during postpartum while $18 \%$ considered it unnecessary. $42 \%$ thought postpartum exercises would be painful. $44 \%$ thought postpartum exercises was less important than child care. $32 \%$ felt there was insufficient support and awareness about postpartum exercises in their family. $44 \%$ felt that doing household work was better than strengthening exercises (Table 2). Over all 52\% of the participants had a positive attitude towards postnatal exercise (Table 2 Fig. 1 ). 
Table 2: Attitude on postnatal exercises among postnatal mothers

\begin{tabular}{|l|c|c|}
\hline \multicolumn{1}{|c|}{ Characteristic } & Yes (\%) & No (\%) \\
\hline Positive attitude towards postnatal exercise & 52 & 48 \\
On necessity of exercise & 82 & 18 \\
Postnatal exercises are painful & 42 & 58 \\
Postnatal exercises are less important than child care & 44 & 56 \\
Household work are better than strengthening exercises & 44 & 56 \\
Insufficient support in family & 32 & 68 \\
\hline
\end{tabular}

\section{Practice of postnatal exercise}

In our study only 58\% practiced postnatal exercises (Table 3 Fig 1). Among them majority (55\%) practiced exercise only during their free time. Only $24 \%$ of them practiced daily. $24 \%$ of them spent less than 2 hours in a week for exercise. More than half, $59 \%$ of them experienced benefits during their course of practice. Among these 59\% of participants, $76 \%$ mentioned loss of weight as the benefit (Table 3).

Table 3: Practice of postnatal exercises among postnatal mothers

\begin{tabular}{|l|c|c|}
\hline \multicolumn{1}{|c|}{ Characteristic } & Yes (\%) & No (\%) \\
\hline Practiced postnatal exercise & 58 & 42 \\
Practice of exercise during free hours & 55 & 45 \\
Daily Postnatal exercises & 24 & 76 \\
Experienced benefits during course of practice & 59 & 41 \\
\hline
\end{tabular}

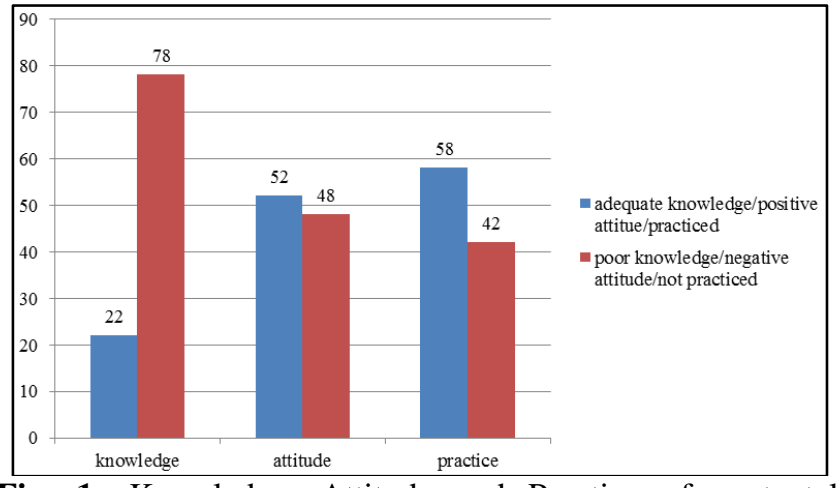

Fig. 1: Knowledge, Attitude and Practice of postnatal exercises among postnatal mothers

Our study showed that knowledge and practice were strongly associated with occupation $(\mathrm{x} 2=23.193, \mathrm{p}=0.000 /$ $\mathrm{x} 2=29.039, \mathrm{p}=0.000)$, education $(\mathrm{x} 2=20.063, \mathrm{p}=0.003$ / $\mathrm{x} 2=24.336, \mathrm{p}=0.000)$ and socioeconomic status $(\mathrm{x} 2=30.098$, $\mathrm{p}=0.000 / \mathrm{x} 2=10.347, \mathrm{p}=0.016)$ but attitude associated only with occupation $(\mathrm{x} 2=25.270, \mathrm{p}=0.000)$ and education $(\mathrm{x} 2=22.449, \mathrm{p}=0.001)$.

\section{Discussion}

$72 \%$ of our study population was aware of the benefits of postnatal exercise, but in a world study by A.F. Adeniyi, O.O. Ogwumike and T.R. Bamikefa et al 'Postpartum Exercise among Women: Issues Relating to Exercise Performance and Self-Efficacy' 61\% were not aware of it. In this study $52.2 \%$ practiced postnatal exercises, in our study it was $58 \%$. Among them $16.8 \%$ only practiced daily, in our study $24 \%$ practiced daily. Compared to this study our study participants had more knowledge and practice of postnatal exercises.

In our study $58 \%$ of the participants were graduates and $22 \%$ had adequate knowledge on postnatal exercises. But in another study done by Asha Sreenivasan et al 'A study to assess the knowledge, practice and attitude of postnatal mother regarding postnatal exercise in government headquarters hospital, south India, only $13.4 \%$ were graduates and $6.7 \%$ had adequate knowledge. In this study only $23.3 \%$ participants had positive attitude but in our study it was $52 \%$. So compared to this study our participants had better knowledge and attitude towards postnatal exercises.

In a study done by *Mr. Swastik Mulay, Mr. Tauphik Khairate, Mr. Kishor Chavan, Mr. Pramod Kondhari, Ms. Anjana Nagargoje **Mrs. Harilakshmi et al 'Assess the knowledge and practice of postnatal exercises among postnatal mothers in selected hospital.' $15 \%$ had good knowledge and $32 \%$ had practiced exercises daily. In this study $88 \%$ were benefited by postnatal exercises, but in our study it was only 59\%. Compared to this study our participants had better knowledge but poor practice.

Another study done by Hawazin Mohammed Alharqi, Dr. Jilan.A. Albattawi et al 'Assessment of Knowledge and Attitude of Women Towards Postpartum Exercise' $72.5 \%$ had adequate knowledge but only $7 \%$ had practiced exercises. So compared to this study our participants had poor knowledge but better practice.

\section{Conclusion}

Data revealed that our participants had poor Knowledge and Practice, but more than half had positive attitude towards the practice of postnatal exercise. Hence health education and awareness programs for pregnant women as well as their family members regarding postnatal exercise must be introduced right from the antenatal period to improve the current scenario. It is the prime role of health care professionals to throw light on the importance of postnatal exercise among them. This study also proved that some demographic variables (education, occupation and 
socioeconomic status) were associated with knowledge, attitude and practice. Among these, occupation and education were the two important factors which influenced the knowledge and practice of postnatal exercise in our participants. So there is a need to improve the educational status of our women which will eventually improve their occupational status.

\section{Limitation}

The study was conducted in a period of 1 month. So the sample size is small.

\section{Recommendation}

1. All women should be informed about the physiological process of recovery after birth.

2. Proper health education regarding postnatal exercise should be given to all antenatal women and their family members attending health facilities.

\section{Source of Funding}

None.

\section{Conflict of Interest}

None.

\section{Reference}

1. Larson-Meyer, D. E. The effects of regular postpartum exercise on mother and child. Int Sport Med J 2003;4(6):1-15.

2. Sreenivasan A, A study to assess the knowledge, practice and attitude of postnatal mother regarding postnatal exercise in government headquarters hospital, Kumbakonam; Int $J$ Adv Sci Res ISSN: 2456-0421; Impact Factor: RJIF 5.32 July 2017;2(4):32-35;www.allscientificjournal.com

3. Sinhgad e-Journal of Nursing, Vol. IV, Issue II, December 2016. 'Assess the knowledge and practice of postnatal exercises among postnatal mothers in selected hospitals'
4. Daley A.J, Jolly K, Sharp D.J, Turner KM., Blamey RV, Coleman S, Macarthur C. The effectiveness of exercise as a treatment for postnatal depression: study protocol. 2012

5. Authors P, Clinical S, Obstetrics P, Society, C, Exercise, F. O. R., Board, P., \& Directors, O. F. Jointsogc / Csep Clin Pract Guideline 2003;(129):1-7.

6. Jancob A: Comprehensive Textbook of midwifery. Second edition 2008.

7. Marcia L.London, Patricia W.Ladewig, Jane W.Ball, Ruth C.Bindler: Maternal and child nursing care, second edition 2005.

8. Scott, S. (n.d.). Exercise in the Postpartum Period, 10(4):40 41.

9. F. Adeniyi, O. O. Ogwumike, and T. R. Bamikefa. Postpartum Exercise among Nigerian Women: Issues Relating to Exercise Performance and Self-Efficacy Hindawi Publishing Corporation, ISRN Obstet Gynecol 2013 Article ID 294518, 7 pages

10. Alharqi HM, Albattawi JA. Assessment of Knowledge and Attitude of Women Towards Postpartum Exercise, IOSR J Nurs Health Sci (IOSR-JNHS)e-ISSN:2320-1959.p- ISSN: 2320-1940 Volume 7, Issue 1 Ver. VIII. (Jan. - Feb .2018), PP $16-20$

11. Faiza.A.N Women's perception and experiences regarding postpartum exercise in Khartoum University Hospitals Khartoum Locality -2015 Sudan, Indian J Appl Res 2016;6(2). ISSN - 2249-555X

12. Chidozie Emmanuel Mbada1, Olubukayomi EbunOluwa Adebayo Practice and Pattern of Antenatal and Postnatal Exercise among Nigerian Women: A Cross-Sectional Study. Int J Women's Health Reprod Sci 2015;3(2):93-98 ISSN 23304456

How to cite this article: Ashok VG, Mohamed A. Knowledge, practice and attitude of postnatal mothers towards postnatal exercises in a rural area of Tamil Nadu. Indian J Forensic Community Med 2019;6(3):134-7. 